\title{
Branching Out through VirtualPREX: Enhancing Teaching in Second Life
}

\author{
Yvonne Masters, Sue Gregory, Barney Dalgarno, Torsten Reiners \\ and Vicki Knox
}

\begin{abstract}
Virtual worlds have been incorporated into the repertoire of higher education teaching and learning for over a decade with numerous reports on the efficacy of this form of learning for both student engagement and enhanced student outcomes. The affordances of these worlds are being used to enhance another aspect of many higher education courses; work integrated learning. In teacher education courses, practice teaching is a core component. However, research has highlighted quality preparation for practice teaching as problematic. This is a particular challenge for distance education students necessitating new approaches to teacher preparation. Virtual world technologies have provided the authors with a capacity to develop $3 \mathrm{D}$ virtual classroom and playground environments. These are currently being tested as effective spaces for developing a range of critical teaching skills prior to pre-service teachers entering a physical classroom. These students have opportunities, through interaction in and with the virtual environment, to practise skills and apply concepts in a risk-free realistic setting. In this chapter, the authors discuss the problems of preparation for practice teaching and the ways in which the virtual world of Second Life is currently being tested as a site for enhanced teacher preparation. The results of the first trials are described and the future of the project explored.
\end{abstract}

Key Words: Second Life, practice teaching, VirtualPREX.

$* * * * *$

\section{Introduction}

In Australia, virtual worlds provide learning opportunities in higher education institutions. ${ }^{1}$ These opportunities transpire because 'virtual worlds are richly immersive and highly scalable $3 \mathrm{D}$ environments' ${ }^{2}$ with a capacity for simulation and extended interactions. ${ }^{3}$ In 2011, a project team of seven researchers from five Australian and one German university commenced trials of an innovative approach to professional experience preparation known as VirtualPREX (Virtual World Professional Experience), utilising these important affordances. VirtualPREX is a two-year project funded by the Australian Learning and Teaching Council.

It is well documented that professional experience is an integral aspect of teacher education courses. ${ }^{4}$ Moreover, 'the implicit value of this component of teacher education is not contested. ${ }^{5}$ However, there are concerns that there is inadequate preparation of pre-service teachers prior to school placements. ${ }^{6}$ 
VirtualPREX is being developed to address these concerns. It also responds to the criticism in an Australian Commonwealth Government report:

The problems with practicum have been outlined in nearly every report addressing teacher education in the last decade. The fact that these problems have still drawn so much attention in this inquiry indicates the need for major reform in this area. ${ }^{7}$

Engagement in VirtualPREX provides pre-service teachers with opportunities to practise their teaching skills, either synchronously or asynchronously, in custombuilt virtual classrooms in Second Life ${ }^{\mathrm{TM}}$. Through role-play, a pre-service teacher can be presented with teaching scenarios that Cruickshank (1969) described as 'the most critical problems he will face in his first year of teaching, in a threat-free, failure-free environment, unlike that of student teaching, ${ }^{8}$ and behaviour management practised 'where failure does not impact the learning of real students. ${ }^{9}$ Role-play and simulations have been advocated in teacher education for over four decades, most commonly in face-to-face mode in tutorials and workshops. ${ }^{10}$ However, web-based simulations are no longer uncommon. ${ }^{11}$ The use of virtual worlds for classroom simulation is one example of such web-based projects. This is an approach to teacher preparation that is relatively untried despite an Australian report recommending that the development of a suite of virtual world schools could provide 'an opportunity to transform the practicum through the use of virtual world simulations so that student teachers are able to experience 'real' teaching situations. ${ }^{12}$ VirtualPREX seeks to redress this situation.

\section{Research Design and Methodology}

VirtualPREX is grounded in the theories of authentic education. Authentic education promotes expert thinking, complex communication, reflective judgment, and problem-solving skills in a risk-free environment. ${ }^{13}$ Learning occurs in environments that provide enhanced learning opportunities due to the ability to 'focus on a limited, but important, number of variables. ${ }^{14}$

The VirtualPREX simulation is designed on the premise that teaching simulations are authentic activities; 'tasks that are identical or similar to those that students will eventually encounter in the outside world. ${ }^{15}$ Instead of memorising situations and potential reaction from books, VirtualPREX is about simulating specific aspects of the total classroom experience. The experienced information is turned into transferable knowledge, preparing pre-service teachers for the complexities of real-life classrooms. The challenge with authentic education in VirtualPREX is about specifying the parameters for the simulated environment, integrating tangible tools for educators and the pre-service teacher to efficiently support the acquisition of skills to react to (un)expected situations. We target first behaviour management because this teaching skill has been reported as being one 
of major concern to pre-service teachers. ${ }^{16}$ In accordance with the nine essential determinants of authentic education, VirtualPREX concentrates on authentic context and tasks, reflection of learned lessons and its authentic assessment, without losing sight of the other determinants. ${ }^{17}$ The theoretical understanding of this project is balanced with the development and implementation of educational processes and tools to provide an authentic experience to the pre-service teacher.

In 2011, a pilot study was undertaken to analyse the efficacy of the research design and to provide the data to inform the revised and expanded design for the major project in 2012. Second Life was the virtual world of choice for pragmatic reasons: ownership of land and familiarity of use. Four classrooms were created where pre-service teachers could practise their teaching skills. 40 primary school student avatars and 8 teacher avatars were custom-created for use in the role-plays.

Role-plays, incorporating a range of student behaviours typically found in a real-life classroom, were developed after a focus-group discussion with eight experienced school teachers and principals. The behaviours described by the teaching practitioners were grouped into 'typical' behaviours (defined as 'good' or 'naughty' as shown in Table1) which became the basis of the role descriptions provided to pre-service teachers in VirtualPREX workshops.

In the first phase of the pilot, five 2-hour workshops were held in a computer laboratory at the University of New England with 72 first year on-campus preservice teachers (61 female; 11 male). Previously in their course, all participants had been provided with a 2-hour tutorial to learn how to operate within Second Life. For the role-plays, the participants were asked to prepare a short teaching episode or idea on teaching ( 7 minutes) on a subject of their choice. The preservice teachers were divided into groups of 6-9 with one person role-playing the teacher and the others role-playing primary school students with the role provided for them based on the list in Table 1.

Table 1 - Typical Behaviours for Role-Plays

\begin{tabular}{|c|c|}
\hline$G$ & \\
\hline $\begin{array}{l}\text { Ideal student in the } \\
\text { classroom } \\
\text { - Good student who generally } \\
\text { behaves, but does not } \\
\text { understand the lesson } \\
\text { - Teacher pleaser - always } \\
\text { tries to do things for the } \\
\text { teacher } \\
\text { - Know-it-all - tries to answer } \\
\text { every question }\end{array}$ & $\begin{array}{l}\text { e - 'dobs' on peers and continuously } \\
\text { stays up late and continually nods off } \\
\text { vn student - will not say or do anything } \\
\text { d student - has other things on mind, }\end{array}$ \\
\hline
\end{tabular}


Each pre-service teacher had the opportunity to act as a teacher once and as a primary school student in other iterations of the role-play. The roles as a primary school student alternated between 'naughty' and 'good.' Rules of the role-play were outlined to all participants in a brief introduction to the structure of the workshop. The communication within the role-plays was through typed text due to the proximity of students in the laboratory.

After analysis of this first phase, the second phase of the trial extended the opportunity to participate to off-campus students. These students were already familiar with Second Life, removing the need for an introductory tutorial. Eight off-campus students ( 6 female and 2 male) accepted the invitation. These roleplays were conducted online, in-world. The teacher role used audio for communication and text was used for the role of primary school students.

The role-plays were captured in multiple ways - video (machinima), text and screenshots. The machinima will be used for review and assessable tasks (see http://www.virtualprex.com/machinima.html for examples).

All participants were asked to complete a survey at the end of each workshop. The survey comprised a range of questions designed to ascertain:

- demographic details such as age and home location;

- student confidence in the use of computers and virtual worlds;

- participant perceptions of the role-play (using a Likert scale).

- participant ratings of the degree to which the role-play was confusing, difficult, irrelevant, interesting, easy to use, useful, boring, and enjoyable (using a Likert scale).

\section{Findings}

The pilot project has provided a wealth of data which will inform the major research project, across four universities, in 2012. The weighted (on- and offcampus) mean ratings for each attribute indicated that, it is perceived as beneficial (see Table 2). In this table negative attributes (columns 1-2) are listed first, followed by positive attributes (useful, easy to use, enjoyable, interesting).

Table 2 - Perceptions of the Role-play (Weighted Mean: $n=80$ ) Adapted 18 $(1=$ not at all, $7=$ extremely $)$

\begin{tabular}{|l|l|l|l|l|l|l|l|}
\hline Attribute & Mean & Attribute & Mean & Attribute & Mean & Attribute & Mean \\
\hline Irrelevant & 3.13 & Difficult & 3.25 & Useful & 4.30 & Enjoyable & 4.64 \\
\hline Boring & 3.23 & Confusing & 3.56 & Easy to Use & 4.60 & Interesting & 4.92 \\
\hline
\end{tabular}

Although the mean responses suggest that on average students perceived that the positive attributes applied to the activity and the negative attributes did not, 
there was substantial diversity in responses and there were a number of students who were less positive about the activity. Some of the open-ended responses from the students provided some indications as to why the role-plays created some negative feedback as shown in Table 3.

Table 3 - Open-ended Responses Identifying Problems with the Activity Everyone chatting at once, losing track of the conversation.

There are behaviour management strategies that involve actions (clapping, hand in the air, etc) which are extremely effective in the classroom but couldn't be used virtually.

Allow less freedom to the avatars which would make it more real as students in a classroom are constantly being monitored, therefore not as much freedom.

Most of the children in my class were disruptive. Some did not listen to instructions at all.

It takes too long to type something. By then the situation you are responding to is gone.

Better technology. Longer teaching period. Use audio instead of text.

These comments are discussed in the next section on the learning from the trial and how it will inform the major project.

There were also many positive comments from participants, particularly in regard to the usefulness of the role-plays in terms of behaviour management and preparing for real-life teaching as shown in Table 4. These comments demonstrate that the role-play has the capacity to enhance the development of teaching skills and to provide an alternative method of preparation to those currently in use.

Table 4 - Positive Open-Ended Responses

Trying different things to keep the students on task, gave us a chance to practise teaching

It was fun and interesting. It gave us time to work on behaviour strategies and management of a class.

You had to deal with a number of students, Some were helpful and others were not. They were just down-right annoying. You got to experience that!

I enjoyed being the teacher and having to come up with strategies to deal with students that would not follow instructions.

Being able to take on the roles of different characters, and being able to understand what it is like to have a class of disruptive students.

In a way it reminds you that not every student will want to learn and they will go to any lengths to get out of it.

Enjoyable to see what others did and how they coped with the situation in a safe environment where you could make mistakes and learn from them. 
The last response commenting on the safety of making mistakes in this environment is very interesting. This has been highlighted as a major advantage of using simulation activities for practising skills without the risk of harm.

The data reported constitute a small sample of the total collected. It contains, however, some of the most crucial data that will be used to refine the role-play for the major project. The learning from these data is discussed in the next section.

\section{Refining the Role-Play}

The pilot highlighted several areas for refinement with decisions to be made about future directions. Refinements such as using audio instead of typed text, at least for the teacher, are easily implemented in non-laboratory workshops and should allow for greater role-play facility for the pre-service teachers. Participants also need to be reminded of the HUD (Heads Up Display) that permits a range of gestures to be used. The HUD was demonstrated at the start of the workshop, but participants forgot this possibility given the comments about not being able to make gestures to control behaviour. Other refinements require different approaches to permit both synchronous and asynchronous use of the classrooms.

Several students reported that their 'classes' seemed to be composed of only non-responsive, 'naughty' children. Re-design of the role-plays has commenced with more careful scripting and the provision of clearer directions. It is possible the novelty of acting the role of a naughty child was responsible for the excessive behaviours displayed, but for the effectiveness of the role-play this needs to be structured more carefully.

A major implementation in 2012 will be the development of bot (non-player character) supported role-play. A schema for scripting the automated role-plays has been developed so that the bots will respond to certain stimuli from the teacher such as being spoken to by name or proximity. This schema will be used to develop a range of scenarios where different behaviours, requiring different teacher approaches, can be targeted.

The addition of bots will enhance the experience for off-campus students who cannot always link up with other students for a 'live' role-play. In this scenario a pre-service teacher will be able to go into a classroom and 'teach,' with bots taking the role of the school children. Furthermore, this capacity for asynchronous teaching moves VirtualPREX into a different domain from those simulations which occur in on-campus tutorial workshops. It also differs from simulations such as TeachLivE which requires trained actors controlling avatars to respond and thus synchronous engagement in the role-play, ${ }^{19}$ but is somewhat similar to the approach used by researchers at the University of Nevada. ${ }^{20}$

\section{Future}

The pilot demonstrated the benefits of the VirtualPREX approach to the preparation of pre-service teachers prior to their exposure of real-life professional 
experience. In 2012, the major project will occur with role-plays of larger numbers of pre-service teachers across several universities.

The major project will also extend into the area of assessment, with machinima being created for reflection and peer assessment. Self, peer and formal assessment possibilities will extend the current preparation of pre-service teachers for professional experience and create greater self-efficacy for those pre-service teachers.

\section{Conclusion}

The VirtualPREX project continues into 2012 with the classrooms, including bots and the role-play scenarios, becoming available for wider use from 2013. 2012 sees the refinement of the role-plays, bot creation, scripting and machinima for assessment. The use of 3D virtual worlds for professional experience practice appears promising, particularly for off-campus students who do not typically have the opportunity to test their skills on their peers. Students wishing to use the virtual world classrooms to practise their teaching skills will have a full suite of 'how to' information available to them from the VirtualPREX website from 2013. More research into the student perceptions of the VirtualPREX classrooms will be undertaken throughout 2012 with the intention of ensuring that a viable $3 \mathrm{D}$ roleplay classroom is available for use by other educators in the future.

\section{Notes}

1 Brent Gregory, et al., 'How Are Australian Higher Education Institutions Contributing to Change through Innovative Teaching and Learning in Virtual Worlds?', in Changing Demands, Changing Directions, eds. Gary Williams, N. Brown, B. Pittard and B. Cleland (Hobart, 2011), 475-590, accessed December 12, 2011, http://www.leishman-associates.com.au/ascilite2011/proceedings.php.

2 New Media Consortium and EDUCAUSE Learning Initiative, The Horizon Report, 2007 Edition (New Media Consortium, 2007): 18.

${ }^{3}$ Steven Warburton, 'Second Life in Higher Education: Assessing the Potential for and the Barriers to Deploying Virtual Worlds in Learning and Teaching', British Journal of Educational Technology 40, No. 3 (2009): 414-426.

${ }^{4}$ Pamela Grossman, Learning to Practice: The Design of Clinical Experience (Washington DC: American Association of Colleges for Teacher Education \& National Education Association, 2010). Kari Smith and Lilach Lev-Ari, 'The Place of the Practicum in Pre-Service Teacher Education: The Voice of the Students', Asia-Pacific Journal of Teacher Education 33, No. 3 (2005): 289-302.

${ }^{5}$ Richard Taffe and Sally Knipe, 'Professional Experience and Undergraduate's Self-Efficacy for Teaching', in Teacher Education: Local and Global, ed. Maxine Cooper (Surfers Paradise, 2005), 423, accessed February 20, 2011, 
http://atea.edu.au/index.php?option $=$ com jdownloads $\&$ Itemid $=132 \& v i e w=$ finish $\&$ cid $=556 \&$ catid $=80 \& \mathrm{~m}=0$.

${ }^{6}$ Donald J. Boyd, et al., 'Teacher Preparation and Student Achievement', Educational Evaluation and Policy Analysis 31, No. 4 (2009): 416-440. Karen Swabey, Geraldine Castleton and Dawn Penney, 'Meeting the Standards? Exploring Preparedness for Teaching', Australian Journal of Teacher Education 35, No. 8 (2010): 29-46.

${ }^{7}$ House of Representatives Standing Committee on Education and Vocational Training. Top of the Class (Canberra: Commonwealth of Australia, 2007), 73, accessed March 30, 2008, http://www.aph.gov.au/house/committee/evt/teachereduc/report.htm.

8 Donald R. Cruickshank, 'The Use of Simulation in Teacher Education: A Developing Phenomenon', Journal of Teacher Education 20, No. 1 (1969): 24.

${ }^{9}$ Lisa Dieker, Michael Hynes, Christopher Stapleton and Charles Hughes, 'Virtual Classrooms: Star Simulator Building Virtual Environments for Teacher Training in Effective Classroom Management', New Learning Technology SALT 4 (2007): 4.

${ }^{10}$ Cruickshank, 'The Use of Simulation in Teacher Education', 23-26.

11 Dieker et al., 'Virtual Classrooms', 1-22. Jean Ann Foley and Gretchen McAllister, 'Making It Real: Sim-School a Backdrop for Contextualizing Teacher Preparation', AACE Journal 13, No. 2 (2005): 159-177. Mark Girod and Gerald Girod, 'Simulation and the Need for Practice in Teacher Preparation', Journal of Technology and Teacher Education 16, No. 3 (2008): 307-337.

${ }^{12}$ Greg Black, Kerrie Smith and Reece Lamshed, Hot Topic: ICT in Pre-Service Teacher Training: Strategic ICT Advisory Service (Adelaide: Education.au Limited; Department of Education, Employment and Workplace Relations, 2009): 33, accessed December 12, 2011, http://dspace.edna.edu.au/dspace/bitstream/2150/54714/1/SICTAS HT preservice.pdf.

13 Jan Herrington, Thomas C. Reeves and Ron Oliver, A Guide to Authentic eLearning (London and New York: Routledge, 2010).

${ }^{14}$ Kathleen W. Ingram and M. Katherine Jackson, 'Simulations as Authentic Learning Strategies: Bridging the Gap between Theory and Practice in Performance Technology', in Association for Educational Communication and Technology (AECT) 2004 International Conference (Chicago, 2004), 299.

${ }^{15}$ Jeanne Ellis Ormrod, Human Learning, $4^{\text {th }}$ Edition (Upper Saddle River, New Jersey: Pearson Education Inc., 2004), 396.

${ }^{16}$ Vern Jones, 'How Do Teachers Learn to Be Effective Classroom Managers?', in Handbook of Classroom Management: Research, Practice, and Contemporary Issues, eds. Carolyn M. Evertson and Carol S. Weinstein (Mahwah, NJ: Lawrence Erlbaum Associates, 2006), 887-903. Sue C. O’Neill, and Jennifer Stephensen, 
'Teacher Classroom Behaviour Management Preparation in Undergraduate Primary Education in Australia: A Web-Based Investigation', Australian Journal of Teacher Education 36, No. 10 (2011): 35-52. Judy Peters, 'First Year PreService Teachers' Learning about Behaviour Management', in AARE International Education Research Conference - 2009, ed. Peter Jeffrey (Canberra, ACT, 2009).

17 Jan Herrington and Ron Oliver, 'An Instructional Design Framework for Authentic Learning Environments', Educational Technology Research and Development 48, No. 3 (2000): 23-48.

18 Yvonne Masters, et al., 'VirtualPREX - Providing Virtual Professional Experience for Pre-Service Teachers', in Virtual Worlds in Open and Distance Education, eds. Sue Gregory, Mark J.W. Lee, Barney Dalgarno and Belinda Tynan (Athabasca University Press: Under review).

19 Synthetic Reality Lab, Institute for Simulations and Training, University of Central Florida, TeachLivE (TeachLivE, 2012), accessed January 16, 2012, http://mclserver.eecs.ucf.edu/teachlive/index.php.

${ }^{20}$ Jennifer Mahon, et al., 'Using Second Life to Enhance Classroom Management Practice in Teacher Education', Educational Media International 47, No. 2 (2010): 121-134.

\section{Bibliography}

Black, Greg, Kerrie Smith, and Reece Lamshed. Hot Topic: ICT in Pre-Service Teacher Training: Strategic ICT Advisory Service. Adelaide: Education.au Limited; Department of Education, Employment and Workplace Relations, 2009.

Boyd, Donald J., Pamela Grossman, Hamilton Lankford, Susanna Loeb, and James Wyckoff. 'Teacher Preparation and Student Achievement'. Educational Evaluation and Policy Analysis 31, No. 4 (2009): 416-440.

Cruickshank, Donald R. "The Use of Simulation in Teacher Education: A Developing Phenomenon'. Journal of Teacher Education 20, No. 1 (1969): 23-26.

Dieker, Lisa, Michael Hynes, Christopher Stapleton, and Charles Hughes. 'Virtual Classrooms: Star Simulator Building Virtual Environments for Teacher Training in Effective Classroom Management'. New Learning Technology SALT 4 (2007): 122.

Foley, Jean Ann, and Gretchen McAllister. 'Making It Real: Sim-School a Backdrop for Contextualizing Teacher Preparation'. AACE Journal 13, No. 2 (2005): 159-177. 
Girod, Mark, and Gerald Girod. 'Simulation and the Need for Practice in Teacher Preparation'. Journal of Technology and Teacher Education 16, No. 3 (2008): $307-337$.

Gregory, Brent, Sue Gregory, Denise Wood, Yvonne Masters, Mathew Hillier, Frederick Stokes-Thompson, Anton Bogdanovych, Des Butler, Lyn Hay, Jay Jay Jegathesan, Kim Flintoff, Stefan Schutt, Dale Linegar, Robyn Alderton, Andrew Cram, Ieva Stupans, Lindy McKeown Orwin, Grant Meredith, Debbie McCormick, Francesca Collins, Jenny Grenfell, Jason Zagami, Allan Ellis, Lisa Jacka, John Campbell, Ian Larson, Andrew Fluck, Angela Thomas, Helen Farley, Nona Muldoon, Ali Abbas, Suku Sinnappan, Katrina Neville, Ian Burnett, Ashleigh Aitken, Simeon Simoff, Sheila Scutter, Xiangyu Wang, Kay Souter, David Ellis, Mandy Salomon, Greg Wadley, Michael Jacobson, Anne Newstead, Gary Hayes, Scott Grant, and Alyona Yusupova. 'How Are Australian Higher Education Institutions Contributing to Change through Innovative Teaching and Learning in Virtual Worlds?'. In Changing Demands, Changing Directions, edited by G. Williams, N. Brown, B. Pittard, and B. Cleland, 475-590. Hobart, 2011. Accessed December 12, 2011.

http://www.leishman-associates.com.au/ascilite2011/proceedings.php.

Grossman, Pamela. Learning to Practice: The Design of Clinical Experience. Washington DC: American Association of Colleges for Teacher Education \& National Education Association, 2010.

Herrington, Jan, and Ron Oliver. 'An Instructional Design Framework for Authentic Learning Environments'. Educational Technology Research and Development 48, No. 3 (2000): 23-48.

Herrington, Jan, Thomas C. Reeves, and Ron Oliver. A Guide to Authentic eLearning. London and New York: Routledge, 2010.

House of Representatives Standing Committee on Education and Vocational Training. Top of the Class. Canberra: Commonwealth of Australia, 2007.

Ingram, Kathleen W., and M. Katherine Jackson. 'Simulations as Authentic Learning Strategies: Bridging the Gap between Theory and Practice in Performance Technology'. In Association for Educational Communication and Technology (AECT) 2004 International Conference. Chicago, 2004. 
Jones, Vern. 'How Do Teachers Learn to Be Effective Classroom Managers?'. In Handbook of Classroom Management: Research, Practice, and Contemporary Issues, edited by Carolyn M. Evertson, and Carol S. Weinstein, 887-903. Mahwah, NJ: Lawrence Erlbaum Associates, 2006.

Mahon, Jennifer, Bobby Bryant, Ben Brown, and Miran Kim. 'Using Second Life to Enhance Classroom Management Practice in Teacher Education'. Educational Media International 47, No. 2 (2010): 121-134.

Masters, Yvonne, Sue Gregory, Barney Dalgarno, Torsten Reiners, and Vicki Knox. 'VirtualPREX - Providing Virtual Professional Experience for Pre-Service Teachers'. In Virtual Worlds in Open and Distance Education, edited by Sue Gregory, Mark J.W. Lee, Barney Dalgarno, and Belinda Tynan. Athabasca University Press. Under review.

New Media Consortium and EDUCAUSE Learning Initiative. The Horizon Report, 2007 Edition. New Media Consortium, 2007.

O'Neill, Sue C., and Jennifer Stephensen. 'Teacher Classroom Behaviour Management Preparation in Undergraduate Primary Education in Australia: A Web-Based Investigation'. Australian Journal of Teacher Education 36, No. 10 (2011): 35-52.

Ormrod, Jeanne Ellis. Human Learning, $4^{\text {th }}$ Edition. Upper Saddle River, New Jersey: Pearson Education Inc., 2004.

Peters, Judy. 'First Year Pre-Service Teachers' Learning about Behaviour Management'. In AARE International Education Research Conference - 2009, edited by Peter Jeffrey. Canberra, ACT, 2009.

Smith, Kari, and Lilach Lev-Ari. 'The Place of the Practicum in Pre-Service Teacher Education: The Voice of the Students'. Asia-Pacific Journal of Teacher Education 33, No. 3 (2005): 289-302.

Swabey, Karen, Geraldine Castleton, and Dawn Penney. 'Meeting the Standards? Exploring Preparedness for Teaching'. Australian Journal of Teacher Education 35, No. 10 (2010): 29-46. 
Synthetic Reality Lab, Institute for Simulations and Training, University of Central Florida. TeachLivE. TeachLivE, 2012. Accessed January 16, 2012. http://mclserver.eecs.ucf.edu/teachlive/index.php.

Taffe, Richard, and Sally Knipe. 'Professional Experience and Undergraduate's Self-Efficacy for Teaching'. In Teacher Education: Local and Global, edited by Maxine Cooper, 423-429. Surfers Paradise, 2005. Accessed February 20, 2011. http://atea.edu.au/index.php?option $=$ com jdownloads $\&$ Itemid $=132 \&$ view $=$ finish $\&$ cid $=556 \&$ catid $=80 \& \mathrm{~m}=0$.

Warburton, Steven. 'Second Life in Higher Education: Assessing the Potential for and the Barriers to Deploying Virtual Worlds in Learning and Teaching'. British Journal of Educational Technology 40, No. 3 (2009): 414-426.

Yvonne Masters is the Director of Professional Experience at the University of New England. Yvonne's research interests are professional experience and virtual worlds, particularly focusing on distance education students.

Sue Gregory is a long term adult educator and Lecturer in ICT in the School of Education at UNE and Chair of the Australian and New Zealand Virtual Worlds Working Group who has been researching Second Life learning since 2007.

Barney Dalgarno is Sub-Dean, Learning and Teaching within the Faculty of Education at Charles Sturt University. His research focuses on ways in which learning can be improved through the use of technology.

Torsten Reiners is a senior lecturer at Curtin University, Perth, Western Australia. His current main research interests are best summarised with Emerging Technologies in Information Systems with a focus on interconnected (virtual) environments.

Vicki Knox is currently a project officer at the University of New England on an ALTC funded project on using 3D virtual worlds with pre-service teachers.

\section{Acknowledgements}

The authors acknowledge the contribution of fellow-researchers: Heinz Dreher, Matthew Campbell and Geoffrey Crisp. They also acknowledge project evaluator, Deanne Gannaway. Support for the research has been provided by the Australian 
Learning and Teaching Council Ltd, an initiative of the Australian Government Department of Education, Employment and Workplace Relations. The views expressed in this chapter do not necessarily reflect the views of the Australian Learning and Teaching Council. 